\title{
Natureza e personagem no cinema latino-americano do novo século
}

AndRea Molfetta

Universidade Federal do Rio de Janeiro/UFRJ

Pesquisadora do CEPECIDOC/UNICAM 


\section{Resumo}

Este texto aborda a grandes traços as características dramatúrgicas dos protagonistas de alguns filmes da mostra de cinema "América Latina: diversidade e semelhança". O texto discute a relação destes sujeitos com a história e com a natureza circundante, diagnosticando uma apatia do sujeito diante do horizonte opressor do colonialismo, ainda em pleno século XXI.

\section{Palavras-chave}

Sujeito, América Latina, Cinema, Apatia, Trauma, Espaço Fî́mico, Colónialismo, Século XXI

\section{Abstract}

The present text involves, in general terms, the acting profile of the characters in some pictures of the Film Festival Latin America: Diversity and Similarity. The study focuses the link between these characters and the history and the environment surrounding them, pointing both a new role of the nature and an apathy of the characters facing the oppressive future of a new colonialism, in the 21 st Century.

\section{Key words}

Character, Latin America, Cinema, Apathy, Trauma, Film Context, Colonialism, 21 st Century 


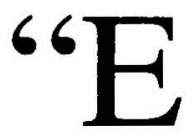

sta geração filma como Hollywood sem culpas" - disse o mexicano Paul Leduc, autor do legendário filme Frida, no centro do programa Roda Viva, da TV Cultura, em 2007.

Vi os filmes da mostra "América Latina: diversidade e semelhança", escrevi algumas anotações sobre eles e, sim, é verdade. Esta geração, a minha, fala o cinema do norte sem questionamentos de linguagem. $\mathrm{Ou}$, ainda mais, quando não são realistas, são hiperrealistas. Casos já famosos do novo cinema mexicano, como Amores Perros, a montagem veloz de Cidade de Deus ou o cinema de Boulocq na Bolivia são exemplos do virtuosismo técnico e da velocidade com que o realismo norte-americano, adotado por nós, incrementa suas potências.

Se 40 anos atrás existia o propósito da arte como ferramenta para a transformação social, objetivos de todos os cinemas novos, hoje o horizonte, as justificativas e, claro, os filmes, são outros. Do ponto de vista político, menos audazes e contestatórios, tanto na forma quanto na construção das personagens, com uma filmografia que aborda os sujeitos na sua intimidade, à procura de um trabalho reflexivo e, ao mesmo tempo, emocional.

Então, já que as formas da sintace filmica deixaram de ser aparentemente o foco da atenção e de experimentação filmica - em relação aos filmes desta mostra - só me resta uma analise da dramaturgia, vale dizer, do nível semântico destès filmes, tanto descrever as personagens quanto falar das características espaço-temporais em que habitam, para assim podermos falar alguma coisa'sobre os objetivos e especulações deste renovado realismo no contexto fílmico latino-americano do novo milênio. 
O foco do cinema narrativo clássico tem sido, desde sempre, o universo interior do protagonista, com quem nos identificamos, fundimos e de quem nos despimos depois. A psicanálise tem realizado uma contribuição histórica dentro da teoria do cinema, em especial, ao desbravar o problema do espectador. São maravilhosos os textos de Bazin sobre o primeiro plano como mergulho psicológico, do livro O que é o cinema; ou os textos de Christian Metz explicando o dispositivo identificatório no cinema a través da transposição dos principais tópicos freudianos, em $O$ Significante Imaginário; os textos do Deleuże sobre o cinema como máquina de emoções, ou sobre o cinema-vidente, no livro Imagem-movimento, sé para citar alguns exemplos deste sempre frutífero encontro entre cinema e psicanálise.

Mas no caso latino-americano contemporâneo, embora a viagem constitui um dos arquétipos mais arcaicos dos processos de transformação dentro da historia da narrativa ocidental, vejo um conjunto de filmes cujas personagens, para resolver seus problemas, estão ou decidem ficar "em trânsito" por este continente no novo século. E , mais que a situação de trãnsito impacta o modo de construir o tempo desta situação, porque não é uma viagem realmente transformadora, nem de si mesmos, nem do contexto . Assim como aparantàm ser viagens sem destinos. Pèlo avesso, os filmes nos mostram uma forma de viajar que é intransitiva .Então, se não há transformação desta perșonagem em trânsito, o que ela faz ao viajar? Esta é a pergunta que direcionou minha analise Como é esțe sujeito que protagoniza os filmes da nossa América Latina?

As personagens Esperançà Tristeza em Qué tan lejos, de Tania Hermida, o casal de Como pasan las Horas, de Inés Cerqueira, o alemão de Cinema, aspirinas e urubus; o próprio cineasta no caso do filme de José Luis Garcia, performativo, ou, por ultimo; o sadorável garoto do $O$ ano que meus pais saíram de férias; do Cao Hamburguer. Todas personagens que, embora se colocam s. si próprias nesta situação de mudança, nem sempre alcançam seus objetivos. Talvez, o desejo de viajar não era delas próprias... Então; o que representa esta metáfora? Que significa viajar para um sujeito impelido a fazê-lo pela sua circunstância social? 
Longe de ser uma viagem desejada e inicitática, é uma viagem de espíritu errante, como quem avança olhando para atrás. Há nas personagens destes filmes, quase sempre, antes que a descoberta, o luto pelo perdido, por aquilo que se deixou atrás. Como viajantes são, de certo ponto de vista, passivos, levados por uma circunstância irremediável que os move: a ditadura, a opressão social sobre a mulher, a insuportável monotonia de um matrimonio ou a supérflua e irremediável condição de turista. Mas nem as motivações da viagem, quanto seus resultados, lhes competem por inteiro a si próprios. Todas são viagens emprendidas por sujeitos que são empurrados pelas suas histórias, e não viagens que o sujeito empreende com espíritu de busca . Estas viagens, mais que um percurso proposto com um ponto de chegada, parecem fugas ou perâmbulos desorientados .

Poderiamos relacionar isto com a experiência do flanneur romântico das grandes urbes, e a atitude melancólica em relação a historia, tal como descrita por Benjamin . Porém, no conjunto destes filmes, este perambular é continental, ao embate da natureza, menos subjetivado.

Em Qué tan lejos (Equador, 2006) temos duas protagonistas que viajam juntas: Esperança, uma jovem espanhola, e Tristeza que na verdade se chama Tereza, mas aceita o equivoco -, uma universitária de Quito . Ambas são apresentadas para nós como estrangeiras: Esperança, obviamente; Tristeza sente-e estrangeira no seu próprio pais ao se relacionar com os índios, habitantes nativos, encontro racial. Ambas encontram-se distantes de uma realidade que observam como verdadeiras estrangeiras, impotentes.

Esperanza comenta surpreendida: "Eu ouço noticias da greve, do corte das estradas... Mas não vejo nada!".

Para Esperança, a turista espanhola, esta realidade latinoamericana é distante, imperceptível, e constitui o corpo da própria Historia: ela é cobrada como conquistadora/opressora durante toda sua incursão no continente . Contudo, Esperança, fiel e merecedora do seu nome, reflete, se detem, questiona e responde, em fim, articulando uma elaboração. Não é o mesmo com a personagem latinoamericana, Tereza/Tristeza, que não consegue seus objetivos e, ainda, fica calada, só epectando passivamente seu próprio fracasso. . 
Para Tristeza, essa realidade distante, diante a qual é impoténte, é o corpo sociàl daquilo que a aliena e asfixia: o padrão social de feminilidade, forçando-a a sofrer rejeições e procurar novos espaços para si mesma..Essa realidade é, para Tristeza, a estruturação conservadora da sociedade equatoriana, em especial, o lugar castrado reservado para a mulher na cultura machista, denunciado na per'manente sexualização do olhar masculino sobre ela e, claro, só verbalizado no comentário da Esperança.. Para Tereza/tristeza, a história social é.oplano presente da sua experiência, e é uma participante-vítima, não-distanciada da situação, somente na revolta frừtrada. A Tristeza só padece. Sente-se alienada e cala, em fim, não impede o casamento do seu ex-noivo, que era seu maior objetivo como personagem desde o inicio do relato.

As duas juntas são como um mandala, fragmentos complementários de uma grande personagem em situação existencial: a Mulher, tão femenina a trama quanto é o próprio nome do nosso continente, América Latina, mistura instável de colonizador e colonizado.

Em Como pasan las horas (Argentina, 2003), de Inés Cardożo Cerqueira, acompanhamos o drama de um casal em desencontro, vivendo uma situação claustrofóbica. Em meio ao vazio que os atormenta, os diálogos indagam novos caminhos para todos os personagens Ao mesmo tempo, cada personagem aparece :isolado visualmente num espaço diferente, para si só . São poụcos os enquiadrámentos compartilhados entre duas personagens:

Neste filme, predominan as cenas nas quais as personagens - estão em situações de solidão ou se deslocamento, também sozinhos. No fundo, um grande clima de èstagnação, ondè toda mudança é desejada, inclusive a morte . Estagnação enfrentáda dramaticamente pelas personagens.

Ele imagina que tudo pode ser diferente. Ela assume que tudo já mudou.

O filme possui um ritmo narrativo no qual as cenas das nossas personagens se alternam com seqüências experimentais de paisagens naturais. Assim, acredito que este binômio estagnação-mudança é representado com a presença mutável, e ao mesmo tempo 
persistente, da natureza. $O$ angustiante, para o espectador, é que o ser humano, no seu enfrentamento e comparação com a condição natural, tece justamente o que há de mais humano: sua auto-transformação desejante, suas crisis, sua cultura, em fim, sua historia. Uma historia diferente, porém igual de imanente, como é a historia natural. Ou poderíamos falar de naturezas rivais? Importa destacar que, mais uma vez, a natureza e a historia aparecem articuladas cinematográfica numa equação dramática original e de grande força estilística.

Este é o segundo tipo de espaço que aparece neste filme: os espaços da natureza, em tempos e durações longas, que fazem $o$ filme entrar numa chave surrealista . As imagens da natureza sofrem uma delicada intervenção formal que nos introduz no plano onírico. Esta intervenção formal está trabalhada no ângulo obtuso das tomadas, que assumem posições de câmera muito interessantes e originais, assim como um cuidado especial na cor e na montagem sonora .

Esta mudança do estatuto do real dentro da narração está atrelada, assim, à experiência da duração do discurso, que torna-se tão lento e denso que nos deixa imersos numa leitura ansiosa e sensível diante quaisquer cambio na imagem do vento, por exemplo, ou do mar. Assim, esta mudança de estatuto está vinculada a imagem da natureza, novamente .

Em Mis más bonitos y mejores años, de Miguel Boulocq (Bolivia, 2005), temos um triângulo amoroso de personagens jovens, sem projetos. Um filme que se oferece como mero aneqdotário de cenas da rua, carros, à noite, cenário da juventude urbana da Bolívia . Aliás, é interessante destacar que todas as personagens aqui abordadas são jovens entre 20 e 40 anos, o que sem dúvidas influi no modo como estes filmes se focalizam no presente, sem sintesis ou questionamentos de profundidade histórica sobre nossa condição latino-americana.

O horizonte da geração boliviana aparece marcado pela idéia de ir embora do país.

A câmera é videográfica, na mão, trabalha no nível da mancha, do traço ráido, cinema direto. Filme no qual tudo acontece em 
torno, dentro ou por um carro: fetiche da industrialização - forânea para a cultura incaica . No final, os jovens não conseguem partir. Neste caso, eles planejam uma viagem que nunca decola, em parte porque aparece outra dimensão da viagem, igual de sinistra e ainda mais frustrante, a das drogas.

Em fim, personagens em deslocamento, em trânsito, e que, finalmente, terminam sua "viagem" sem muita transformação . Apatia, falta de esperança, opressão lá no íntimo, foi isso que encontrei como dramas destas personagens que se colocam neste tipo de deslocamentos.

Em relação a analise espacial, a dupla cidade/campo me surpreendeu, porque acredito que a Natureza continua sendo um âmbito de destaque. Os filmes. puramente urbanos são poucos, a minoria dentro da mostra . Mas desta vez, a natureza não é mais um grande símbolo da potencia da Nação, discursos ainda iluminados pela perspectiva desenvolvimentista das metrópolis capitalistas: Desta vez, a natureza é um espaço de auto-reflexão, de encontro rivalizante com a identidade. No fundo, a natureza é o cenário de deslocamentos desorientados que indagam nossa identidade no século XXI.

E o que, justamente, nos cria neste conjunto de filmes a dupla sujeito-natureza? Personagens em viagens de auto-reconhecimento, fotografando a atual América Latina. Esta relação com a natureza torna-se absoluta na paradigmática cena do filme "Que tal Lejos", quando cinco criancinhas surgem do nada.

Do nada? Nada, ou, sem nome? É a nada, ou é o incógnito, o inominável? Novamente, um exemplo de detenção temporal, que nos alerta sensivelmente sobre el lento pulsar da inércia do plano imanente. Momentos de detenção temporal que acontecem, nos dois casos exemplificados nos filmes de Hermida e Cerqueira, em relação à Natureza .

Assim, acredito que isto pode sim ser ainda um parâmetro diferenciador: não é mais a natureza em si, como monumento simbólico, como representação metafórica do potencial da Nação, tal como acontecia na paisagem cinematográfica dos anos 40 e 50 , e que não faziam mais que reproduzir os discursos dos estados-nação que nos colonizaram. Hoje temos, em troca, na nossa cinematografia, o caráter 
relacional do sujeito latino-americano com essa paisagem, que se oferece mais como espaço de perguntas que de respostas.

Quero dizer que estas personagens vivem estas detenções, justamente quando estão em trãnsito. Contraste ou contraponto muito barroco, tanto quanto o ato estético-filmico de descentrar-se para se encontrar a si próprio, diante do vazio destas personagens. Paradas reflexivas que, definitivamente, pela dilatação da duração a que nos expõem, enrarecem a relação com a história, que sempre aparece como algo distante que alcança a personagem para faze-la padecer, como Historia de opressão, monolítica e sem direito a reposta .

Se a narrativa do cinema clássico representa um Tempo da Historia num Tempo do Discurso quaisquer - um bloco de historia inscrito numa duração discursiva -, as narrativas audiovisuais modernas ensaiam a possibilidade de obstruir o acesso a história através do obstáculo da reflexividade, nos expondo à leitura de um tempo discursivo puro, puro relato, ritmo narrativo que Genette chamara de pausa, e que é absolutamente transtornador para o espectador, que deve decidir o rumo da sua leitura sem referente. Isto que para o autor de Figures III é um ritmo narrativo chamado de pausa, para Deleuze é resultado, no cinema moderno, do trauma gerado pela impotência coletiva vivenciada durante a Segunda Guerra Mundial. Vale dizer, repito, uma pausa, que é sintoma de um trauma.

Acredito que, no caso latino-americano, esta pausa que surge no contato com a natureza se apresenta fazendo da nossa história um mero plano de imanência, naturalizando uma situação opressiva e ainda colonial, naturalizando o que foi e é histórica e politicamente construído, o qual é certamente perigoso e nos diz, a gritos, que perdemos a chance de narrar desde nosso próprio ponto de vista póscolonial . Nesse sentido, parece que esta estética cinematografica possui uma dívida crítica com nosso contexto, o que faz sentido com a denuncia do Leduc citada acima, pecado do realismo .

A história não aparece como um campo de ação e intervenção. Os filmes situam-se todos no presente atual, todos sem exceção, sem realizar sintesis ou julgamentos históricos. Não há perspectiva histórica ou política nem nos assuntos, nem na abordagem da historia das personagens nestes relatos. $\mathrm{E}$ vejo isto como um sintoma peculiar nosso ou, mais que como um sintoma, como uma cicatriz. 


\section{Bibliografia}

DELEUZE, Gilles, A Imagem-Movimento, SP: Brasiliense, 1983.

, Conversações, RJ: Editora 34, 1992.

GENETTE, Gerárd, Figures' III, Paris; Seuil, 1972.

GWENDOLYN/AUDREY/FOSTER, Captive Bodies, Postcolonial Sübjectivity in Cinema, Albany: State University of New York Press, 1999.

METZ, Chritian, O Significante Imaginário. Psicanálise e Cinema. Lisboa: Livros Horizonte, 1973-76.

, L'ennonciation impersonnelle, ou Le Site du Film., París:Méridiens Klincksieck; 1991. 